\title{
Variations in Origin and Course of Cystic Artery and Its Relation with Calot's Triangle.
}

\author{
Dr.Rita kumari ${ }^{1}$, Dr.Shobha kumari ${ }^{1}$, Mrs.Atulya prasad ${ }^{1}$, \\ Dr.N.Jacques britto ${ }^{1}$, Dr Subratanag ${ }^{2}$ \\ ${ }^{1}$ Department ofAnatomy, AIIMSPatna, Bihar, India \\ ${ }^{2}$ Department ofAnaesthesia, NMCH, Rohtas, Bihar, India
}

\begin{abstract}
Anatomical variations in the origin and course of cystic artery are very common which is encountered during surgical and laparoscopic procedures. The knowledge of relevant anatomy of this region is very important for safe execution of cholecystectomy and other procedures. Misinterpretation of anatomy and presence of anatomical variations can lead to major intraoperative and post-operative complications.

In present study a unique origin of cystic artery was found in one cadaver. Here cystic artery was directly arising from the abdominal aorta just below the origin of coeliac trunk. In another cadaver the source of origin of cystic artery was from proper hepatic artery instead of right hepatic artery.

Keywords: Cystic artery, Right hepatic artery, Calot's triangle, Anatomical variations, Cholecystectomy.
\end{abstract}

\section{Introduction}

The cystic artery usually arise from right hepatic artery which is a branch of proper hepatic artery. Commonly cystic artery is single in number but sometimes double cystic artery can be found. It usually passes posterior to common hepatic duct and anterior to cystic duct to reach the superior aspect of neck of the gall bladder, then it divides into superficial and deep branches and supply the gall bladder. The cystic artery may arise from proper hepatic artery, common hepatic artery, sometimes from gastroduodenal or superior mesenteric artery. An accessory cystic artery may arise from common hepatic artery, gastroduodenal artery or superior mesenteric artery.

Calot's triangle is very important landmark for intraoperative localization of cystic artery. It is bounded superiorly by the inferior surface of segment $\mathrm{V}$ of liver, inferiorly by cystic duct and medially by common hepatic duct.

Variations of the origin and course of the cystic artery are very common. Now a day's laparoscopic cholecystectomy became the gold standard for treatment of cholelithiasis; so knowledge of anatomical variations of hepatobiliary arterial system is very important. Cystic artery haemorrhage during laparoscopic cholecystectomy can result in conversion to open surgery. So awareness of other possible variations in this region is of paramount importance for safe cholecystectomy.

\section{Material and Methods}

The dissection was carried out in 36 male and female preserved cadaver during routine educational dissection for undergraduate students in the department of anatomy RIMS, Ranchi and DMCH, Darbhanga. Abdomen was opened as per Cunningham's manoeuvre, cystic duct, right and left hepatic duct, common hepatic duct, common bile duct were traced and dissected out. Boundaries of Calot's triangle were defined cystic artery, right hepatic artery, proper hepatic artery, common hepatic artery were identified. The origin and course of cystic artery was traced in relation to duct system and to Calot's triangle. Variations found were noted and photographed.

\section{Observation}

In present study 36 cadaver were dissected and studied. Out of 36 cadaver, in one cadaver (2.78\%) we found that the cystic artery was originating directly from abdominal aorta just below the coeliac trunk. The cystic artery was running downward, forward and towards the right side behind the portal vein, common hepatic duct and cystic duct. Then it reaches to neck of gall bladder where it divides into superficial and deep branches to supply the gall bladder. No other cystic artery was arising from the branches of coeliac trunk.

Apart from this, in one specimen $(2.78 \%)$ we found that the cystic artery was originating from proper hepatic artery. Much higher division of proper hepatic artery in right and left hepatic artery was noted. In this specimen length and diameter of cystic artery was much more than that of the other specimens. Cystic artery was running anterior to common hepatic duct and at the neck of gall bladder it divides into superficial and deep branch and then enters into the wall of gall bladder to supply it. Diameter of common hepatic duct, cystic duct and common bile duct was also more than the other specimens.

DOI: 10.9790/0853-150752427 www.iosrjournals.org $\quad 24 \mid$ Page


Variations In Origin And Course Of Cystic Artery And Its Relation With Calot's Triangle.

In the rest 34 cases $(94.44 \%)$ the cystic artery was originating from right hepatic artery. Out of 34 cadaver, in 3 cadaver $(8.82 \%)$ the source of origin of cystic artery was out of Calot's triangle and in 31 cadaver $(91.17 \%)$ source of origin of cystic artery was inside the Calot's triangle.

In the above mentioned 2 cases the origin of cystic artery was also outside the Calot's triangle. So overall in 5 cadaver $(13.89 \%)$ the source of origin of cystic artery was outside the Calot's triangle and in 31 cadaver $(86.11 \%)$ the source of origin of cystic artery was inside the Calot's triangle.

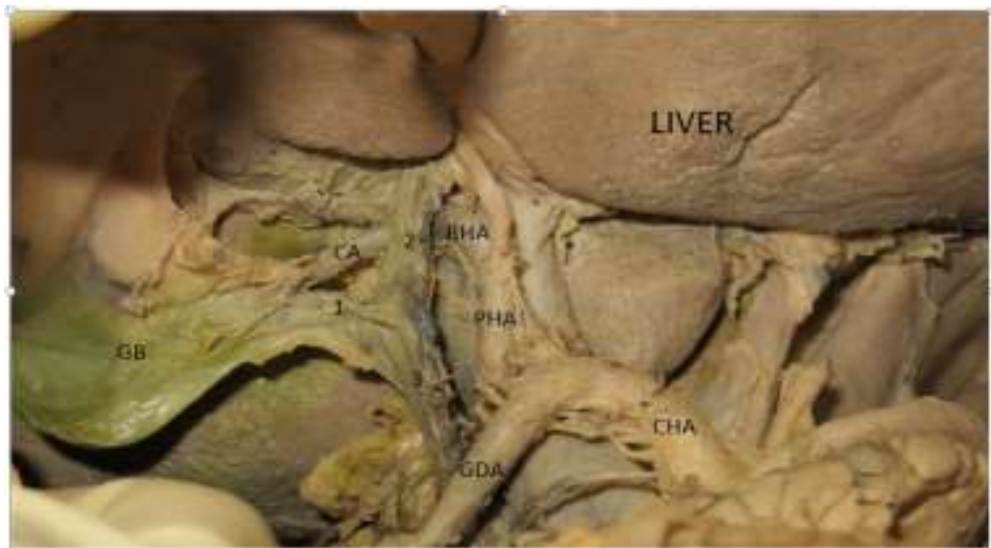

Fig 1: Showing normal origin of cystic artery from right hepatic artery inside the Calot's triangle.GB: Gall bladder, CA: Cystic artery, RHA: Right hepatic artery, PHA: Proper hepatic arteryCHA: Common hepatic artery, GDA: Gastroduodenal artery, 1: Cystic duct, 2: Common hepatic duct, 3: Common bile duct

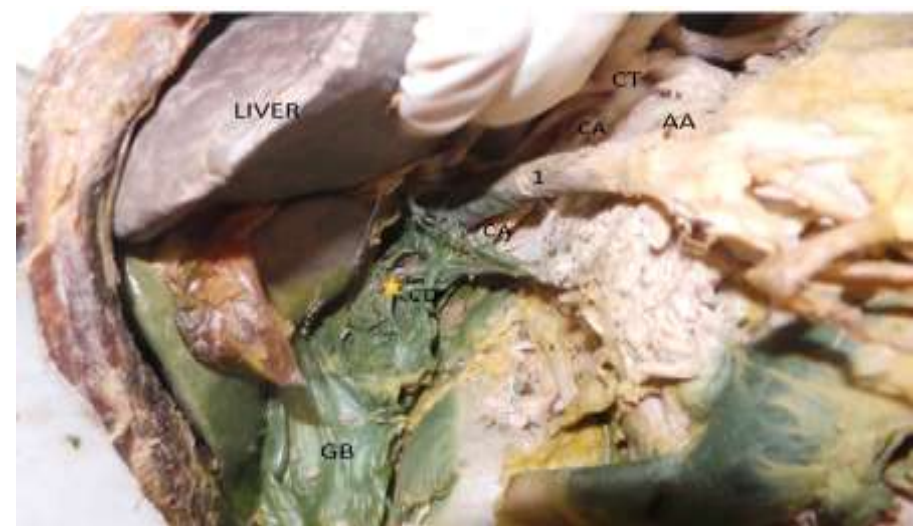

Fig 2: Showing anomalous origin of cystic artery from abdominal aorta below the origin of coeliac trunk.CT:

Coeliac trunk, AA: Abdominal aorta, CA: Cystic artery, CD: Cystic duct, GB: Gall bladder

1: Portal vein, Yellow star mark showing cystic artery which divides into superficial and deep branch.

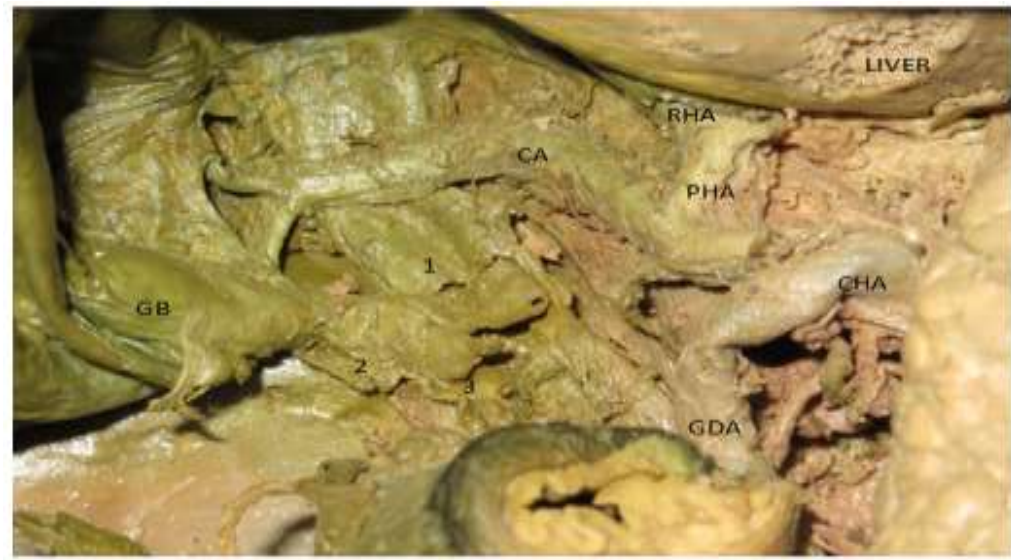

Fig 3: Showing origin of cystic artery from proper hepatic artery outside the Calot's triangle. CA: Cystic artery dividing into superficial and deep branch, PHA: Proper hepatic artery, CHA: Common hepatic artery, GDA: Gastroduodenal artery, GB: Gall bladder, RHA: Right hepatic artery.

1: Common hepatic duct, 2: Cystic duct, 3: Common bile duct. 


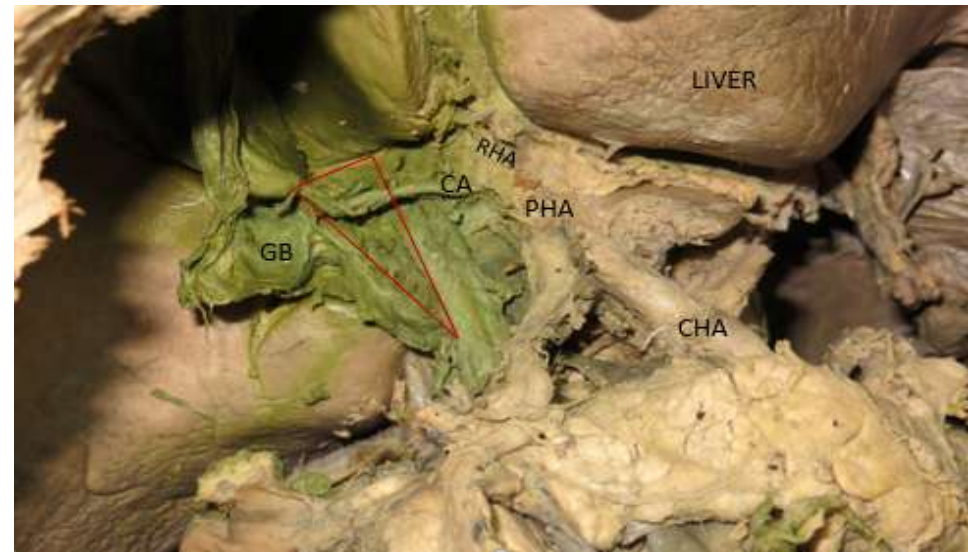

Fig 4: Showing origin of cystic artery from right hepatic artery outside the Calot's triangle. CA: Cystic artery, RHA: Right hepatic artery, CHA: Common hepatic artery, GB: Gall bladder, PHA: Proper hepatic artery.

\section{Discussion}

Variations in origin and course of cystic artery are very common. Sometime 2 cystic artery can be seen in Calot's triangle as reported by some authors. Knowledge and awareness of these variations are very essential for surgeons to avoid intraoperative and postoperative complications. In most cases cystic artery originates from right hepatic artery. But it may arise from left hepatic artery, proper hepatic artery, common hepatic artery, gastroduodenal artery or superior mesenteric artery. There may be some embryological basis behind it.

In $3^{\text {rd }}$ week of intrauterine life liver and gall bladder develops from hepatic diverticulum that arise from distal end of fore gut. This diverticulum is richly supplied by branches of abdominal aorta. But most of the vessels degenerate during development. This degeneration pattern is highly variable resulting in variations in blood supply of liver and gall bladder. Source of origin of cystic artery is also variable as reported by different authors and it is shown in table given below.

Table: 1camparison of Source of Origin of Cystic Artery with Other Studies

\begin{tabular}{|c|c|c|c|c|c|c|c|c|c|c|}
\hline \multirow[t]{2}{*}{ SI.No. } & \multirow[t]{2}{*}{ Studies } & \multirow{2}{*}{$\begin{array}{l}\text { No. of } \\
\text { cases } \\
\text { studied }\end{array}$} & \multicolumn{7}{|c|}{ Source of origin } & \multirow[b]{2}{*}{ SMA } \\
\hline & & & RHA & PHA & LHA & GDA & CHA & CT & ABRHA & \\
\hline 1. & Flisinski et al. & 34 & $82.3 \%$ & $8.8 \%$ & $5.8 \%$ & $2.9 \%$ & 0 & 0 & 0 & 0 \\
\hline 2. & Flint ER & 200 & $98 \%$ & 0 & 0 & $0.5 \%$ & $1.5 \%$ & 0 & 0 & 0 \\
\hline 3. & Daseler et al. & 580 & $71.7 \%$ & 0 & $6.2 \%$ & $2.6 \%$ & $2.7 \%$ & $0.35 \%$ & $16 \%$ & 0 \\
\hline 4. & Michels NA & 200 & $77.5 \%$ & 0 & $5 \%$ & $4 \%$ & $1.5 \%$ & $0 \%$ & $12 \%$ & 0 \\
\hline 5. & Desilva et al. & 50 & $96 \%$ & 0 & $4 \%$ & 0 & 0 & 0 & 0 & 0 \\
\hline 6. & Khalil M & 60 & $90 \%$ & $2 \%$ & $3 \%$ & $2 \%$ & $3 \%$ & 0 & 0 & 0 \\
\hline 7. & K. Pushpalatha & 50 & $54 \%$ & $22 \%$ & 0 & $8 \%$ & $12 \%$ & 0 & 0 & $2 \%$ \\
\hline
\end{tabular}

RHA: Right hepatic artery, PHA: Proper hepatic artery,

LHA: Left hepatic artery,

GDA:Gastroduodenal artery,

CHA: Common hepatic artery,

CT: Coeliac trunk,

ABRHA: Aberrant right hepatic artery, SMA: Superior mesenteric artery.

Calot's triangle is very important landmark for surgeons for identifying cystic artery during cholecystectomy. Usually cystic artery arise from right hepatic artery inside the Calot's triangle but may also arise outside the Calot's triangle.

Table: 2Comparison of Relation of The Cystic Artery to the Calot's Triangle with the Other Studies

\begin{tabular}{|l|l|l|l|l|}
\hline Sl.no. & studies & No.of cases studied & \multicolumn{2}{l|}{ Relation to the Calot's triangle } \\
\cline { 3 - 5 } & & & $\begin{array}{l}\text { Inside Calot's } \\
\text { triangle }\end{array}$ & Outside Calot's triangle \\
\hline 1. & Flinsnskiet al. & 34 & $97.06 \%$ & $2.94 \%$ \\
\hline $\mathbf{2 .}$ & Michels NA & 200 & $81 \%$ & $19 \%$ \\
\hline 3. & Daseler et al. & 580 & $69.80 \%$ & $31.20 \%$ \\
\hline
\end{tabular}


Variations In Origin And Course Of Cystic Artery And Its Relation With Calot's Triangle.

\begin{tabular}{|l|l|l|l|l|}
\hline 4. & Desilva et al. & 50 & $70 \%$ & $30 \%$ \\
\hline $\mathbf{5 .}$ & Futura et al. & 110 & $89 \%$ & $11 \%$ \\
\hline
\end{tabular}

In 2009 Bakheit MA documented variations in origin of cystic artery and its relation to Calot's triangle in Sudanese people. He found that the origin of cystic artery was more from common hepatic artery in Sudanese(17\% versus 3\% in Caucasians); the origin was in Calot's triangle in $25 \%$ cases where as in Caucasians $70 \%$ cystic artery were arising in Calot's triangle.

In 2012 Rajashekhar Y Dundaraddy studied vascular variations in extra hepatic region and he found that the origin of cystic artery inside the Calot's triangle in $37.5 \%$ and outside the Calot's triangle was in $62.5 \%$ cases.S. Aristotle (2014) he studied 40 cases and in 37 cases cystic artery arouse from right hepatic artery, 1 from common hepatic artery and in 2 cases from proper hepatic artery.

Md. Khaleel ahmed et al (2015) they studied over 60 cadaver and observed that in 57 cases cystic artery originated from right hepatic artery, in 2 cases from accessory hepatic artery and in 1 case from gastroduodenal artery and in 1 case double cystic artery was present.

Hossein et al (2015) he studied variations of gall bladder vasculature and he found double cystic artery. One cystic artery was arising from right hepatic artery and accessory cystic artery was arising from gastroduodenal artery.

Awareness of variations in blood supply of hepatobiliary apparatus is very essential now a days due to recent development of certain fields of abdominal surgery such as laparoscopic cholecystectomy, choledocal carcinoma treatment,cholangiojejunostomy and all other hepatobiliary surgical procedures.

\section{Conclusion}

Thuslots of variations are found in blood supply of liver and gall bladder. Knowledge of these variations are very essential for diagnostic and surgical interventions.

\section{References}

[1]. Standring S ,Ellis H , Healy JC Johnson D, Williams A ,Collins P ,et al .Gray's Anatomy ,The anatomical basis of clinical practice $40^{\text {th }}$ ed .New York.pg. 1179

[2]. Flint ER.Abnormalities of the right hepatic ,cystic and gastroduodenal arteries and of the bile ducts.Br JSurg 1923;10:509-19

[3]. Daseler EH, Anson BJ, Hambley WC,Riemann AF.The cystic artery and constituents of the hepatic pedicle. Surg Gynecol Obst $1947 ; 85: 47-63$

[4]. Michels NA, variation anatomy of the hepatic, cystic and retroduodenal arteries.A statistical analysis of their origin ,distribution \& relation to the biliary ducts in two hundred bodies .Arch Surg $1953 ; 66: 20-34$

[5]. Desilva M, Fernando D. Anatomy of the Calot's triangle and its relevance to laparoscopic cholecystectomy. Ceylon Mec t J2001;46(1):33-4

[6]. Futura G, Ali A, Kinfu Y. Variations of the hepatic and cystic arteries among Ethiopians. Ethiop Med J 2001 Apr;39 (2):133-42

[7]. .Flisinski P, Szpinda M, Flisinski M. the cystic artery in human foetuses. Folia Morphol 2004 ;63 (1): 47-50

[8]. Khalil M ,Sultana ZR ,Rahman HR ,Sultana SZ, Mannan S , Rahman MM ,et al.Origin and positioning of cystic artery in Bangladeshi Corpse. J Bangladesh Socphysio 2008 Dec; 3:66-70

[9]. Bakheit M A. Prevalence of variations of the cystic artery in Sudanese. East Mediterr Health J 2009; 15 (5):1308-12

[10]. Pushpalatha, Shamsunder NM. Variation in the origin of cystic artery J.Anat Soc India $2010 ; 59$ (1):35-7

[11]. Rajashekhar Y Dundaraddy, G M Mahesh: Vascular variations in extrahepatic biliary system. BM journal: vol 3, March 2012, page 8-10.

[12]. Patil S, Rana K, Kakar S, Mittal A. Origin of cystic artery from hepatic artery proper and its surgical implications. Int J Res Med Sci. 2013; 1(1): 16-18.

[13]. Aristotle S: Variation in origin and course of cystic artery and its relation to Calot's triangle with its clinical implications. OA Anatomy 2014 Jul 18:2(2):17

[14]. Md. Khaleel Ahmed, Sarita Sylvia, Origin of cystic artery \& its position in relation to biliary duct \&Calot's triangle. Journal of evolution of Medical \& Dental sciences 2015; volume 4, issue 01, January 01; page 1-5.

[15]. Hossein Eyni et al: Variation of the gall bladder vasculature including double cystic arteries. Anatomical sciences, Feb 2015, volume 12, number 1, page no. 51-54. 